The Canadian Mineralogist

Vol. 44, pp. 1079-1087 (2006)

\title{
THE OXIDATION STATE OF EUROPIUM IN HYDROTHERMAL SCHEELITE: IN SITU MEASUREMENT BY XANES SPECTROSCOPY
}

\author{
JOËL BRUGGER ${ }^{\S}$ \\ School of Earth and Environmental Sciences, University of Adelaide, Adelaide, SA 5005, \\ Australia and South Australian Museum, North Terrace, Adelaide, SA 5000, Australia \\ BARBARA ETSCHMANN \\ CSIRO Exploration and Mining, South Australian Museum, North Terrace, Adelaide, SA 5000, Australia \\ YoNG S. CHU \\ Experimental Facilities Division, Advanced Photon Source, Argonne National Laboratory, \\ 9700 South Cass Avenue, Argonne, Illinois 60439, USA \\ CATHY HARLAND \\ Australian Synchrotron Research Program (ANSTO), Advanced Photon Source, Argonne National Laboratory, \\ 9700 South Cass Avenue, Argonne, Illinois 60439, USA

\section{STEFAN VOGT} \\ Experimental Facilities Division, Advanced Photon Source, Argonne National Laboratory, \\ 9700 South Cass Avenue, Argonne, Illinois 60439, USA

\section{CHRIS RYAN}

CSIRO Exploration and Mining, School of Geosciences, Building 28E, Monash University, Clayton, Victoria 3168, Australia

\author{
HUGH JONES
}

School of Earth and Environmental Sciences, University of Adelaide, Adelaide, SA 5005, Australia

\section{ABSTRACT}

$\mathrm{X}$-ray microfluorescence and $\mathrm{Eu} L_{3}$ micro-X-ray absorption near-edge structure (XANES) spectroscopy were conducted to determine the distribution and valence state of europium in two samples of scheelite $\left(\mathrm{CaWO}_{4}\right)$ containing between 40 and 350 ppm Eu. The samples come from hydrothermal gold deposits: the Archean Drysdale deposit in Kalgoorlie, Western Australia (DRY1) and the Caledonian, intrusion-related Stepnyak deposit in Kazakhstan (USP31). Laser-ablation ICP-MS analyses reveal that both samples are characterized by bell-shape chondrite-normalized REE patterns with a maximum enrichment around Eu, and a small positive or no Eu anomaly. USP31 displays a complex zoning between this pattern and a strongly LREE-enriched pattern with a strong positive Eu-anomaly. The XANES spectroscopy reveals the coexistence of $\mathrm{Eu}^{2+}$ and $\mathrm{Eu}^{3+}$ in both scheelite samples DRY1 and USP31. The oxidation of Eu in USP31 appears to be inhomogeneous within a single crystal, with zones containing a mixture of $\mathrm{Eu}^{2+}$ and $\mathrm{Eu}^{3+}$ and zones containing more than $90 \% \mathrm{Eu}^{2+}$. This study shows that it is possible to obtain semiquantitative element-distribution maps for LREE as well as, in optimal conditions, Eu $L_{3}$ XANES spectra on a bending magnet beamline equipped with a solid-state detector.

Keywords: X-ray absorption near-edge spectroscopy (XANES), scheelite, europium, oxidation state, rare-earth elements, elemental mapping, gold deposit.

\footnotetext{
$\S \quad$ E-mail address: joel.brugger@adelaide.edu.au
} 


\section{SOMMAIRE}

Afin de caractériser la distribution et l'état d'oxydation de l'europium dans deux échantillons de scheelite $\left(\mathrm{CaWO}_{4}\right)$ contenant entre 40 et $350 \mathrm{ppm} \mathrm{Eu}$, nous avons effectué des analyses par micro-fluorescence X ainsi que par l'étude de la structure fine du seuil d'absorption $L_{3}$ de l'europium obtenue par microspectroscopie des rayons X. Les échantillons proviennent de gisements aurifères hydrothermaux: le gîte Archéen de Drysdale à Kalgoorlie, Australie occidentale (DRY1), et le gîte Calédonien lié à une intrusion de Stepnyak, au Kazakhstan (USP31). Les analyses par ablation au laser - ICP-MS montrent que les deux échantillons possèdent des spectres de terres rares (normalisés par rapport aux chondrites) en cloche avec un enrichissement maximum au niveau de l'Eu, et une faible anomalie positive ou aucune anomalie en Eu. USP31 possède une zonation complexe, les domaines variant de ce spectre à un spectre fortement enrichi en terres rares légères avec une forte anomalie positive en Eu. La spectroscopie XANES révèle la coexistence d'Eu ${ }^{2+}$ et $\mathrm{Eu}^{3+}$ dans les deux échantillons. L'état d'oxydation de l'Eu dans USP31 semble être inhomogène au sein d'un même cristal, avec des zones contenant un mélange de $\mathrm{Eu}^{2+}$ et $\mathrm{Eu}^{3+}$ et des zones contenant plus de $90 \% \mathrm{~d}^{\prime} \mathrm{Eu}^{2+}$. Cette étude montre qu'il est possible d'obtenir des cartes de distribution des terres rares légères ainsi que, dans des conditions optimales, des spectres XANES Eu $L_{3}$ en utilisant une ligne sur aimant de courbure ainsi qu'un détecteur opérant à l'état solide.

Mots-clés: structure fine du seuil d'absorption de rayons X (XANES), scheelite, europium, état d'oxydation, terres rares, distribution des éléments, gisements d'or.

\section{INTRODUCTION}

Tracking the oxidation state of ancient hydrothermal fluids is fundamental for our understanding of the physicochemical conditions of ore transport and deposition in many $\mathrm{Cu}, \mathrm{Au}, \mathrm{Zn}, \mathrm{Pb}$, or $\mathrm{U}$ deposits (e.g., Heinrich et al. 1996). Geologists rely mainly on mineral assemblages to estimate redox conditions in ancient hydrothermal systems. However, stability fields of minerals commonly cover large ranges in redox conditions. Moreover, in cases of complex polyphase mineralization, it can be difficult to relate one particular assemblage to a particular stage of mineralization. The oxidation state of trace elements incorporated in hydrothermal minerals may provide an additional tool to estimate the redox state of ancient fluids. In this paper, we explore the use of in situ X-ray absorption nearedge structure (XANES) microspectroscopy to measure the oxidation state of europium in scheelite from gold deposits at $7 \times 7 \mu \mathrm{m}^{2}$ resolution, and show that the samples studied contain a mixture of $\mathrm{Eu}^{2+}$ and $\mathrm{Eu}^{3+}$.

\section{RARE-EARTH ELEMENTS AND SCHEELITE IN HYDROTHERMAL SYSTEMS}

Rare-earth elements (REE) occur as trivalent cations in nature, and behave in a consistent manner during geochemical processes such as melting, fractional crystallization, transport in a fluid, phase separation, and coprecipitation. Fractionation among the REE is caused by a slight systematic decrease in ionic radius from La to $\mathrm{Lu}$, and by changes in oxidation states for some REE. In particular, $\mathrm{Eu}^{2+}$ exists under reducing conditions; its stability in aqueous solutions increases with increasing temperature (Sverjensky 1984, Haas et al. 1995).

The REE are well established as petrogenetic indicators in magmatic systems (e.g., Lipin \& McKay 1989). Europium is used to estimate redox conditions in such systems; however, the ratio $\mathrm{Eu}^{2+} / \mathrm{Eu}^{3+}$ is rarely measured directly, and only the so-called europium anomaly, based on the variation in total Eu relative to neighboring REE, is used. The REE and the europium anomaly are also commonly used in the study of hydrothermal systems; however, their use has been hindered by the complexity of the controls on REE fractionation in such environments (Bau 1991, Gieré 1996). Direct measurement of the $\mathrm{Eu}^{2+} / \mathrm{Eu}^{3+}$ value in tracer minerals may provide a sensitive probe into redox conditions at the time of mineral growth, and would constrain the interpretation of the Eu anomaly in these minerals.

Scheelite $\left(\mathrm{CaWO}_{4}\right)$ is a common accessory mineral in various types of gold mineralization (e.g., Uspensky et al. 1998). Scheelite incorporates tens to thousands of ppm REE in substitution for Ca (e.g., Brugger et al. 2000b). The wide distribution of scheelite in Au-bearing systems and its close association with deposition of gold make it an excellent candidate as a tracer of the composition of the Au-bearing fluids and Au-deposition processes (Uspensky et al. 1998, Brugger et al. 2000a, b). Scheelite also is useful for dating ore deposition by means of the radioactive decay of ${ }^{147} \mathrm{Sm}$ to ${ }^{143} \mathrm{Nd}$ (half life $106 \mathrm{Ga}$; e.g., Anglin et al. 1996, Brugger et al. 2002, Eichhorn et al. 1997, Ghaderi et al. 1999).

\section{Eu $L_{3}$ XANES Spectroscopy of Minerals}

The XANES spectra at the $L_{3}$-edge of Eu can be used to determine the valence state of europium in the sample. Well-resolved edge-resonance peaks at 6973.7 and $6981.7 \mathrm{eV}$ are attributed to electron transitions between the $2 \mathrm{p}_{3 / 2}$ and the $5 \mathrm{~d}$ states in $\mathrm{Eu}^{2+}$ and $\mathrm{Eu}^{3+}$, respectively (Rakovan et al. 2001, and references therein). However, the collection of Eu XANES data (Eu $L_{3}$-edge $6977 \mathrm{eV}, \mathrm{Eu} L \alpha_{1} 5849.5 \mathrm{eV}$ ) on natural minerals is made difficult by interferences by manganese ( $K$-edge $6539 \mathrm{eV}, K \alpha_{1} 5900.3 \mathrm{eV}$ ) and neodymium ( $L_{3}$-edge $6208 \mathrm{eV} ; L \alpha_{1} 5227.6 \mathrm{eV}, \mathrm{L} \beta_{1}$ $5721.1 \mathrm{eV}, L \beta_{3} 5828.1 \mathrm{eV}$ ), which cannot be resolved 
with solid-state detectors (energy resolution $\sim 150 \mathrm{eV}$ ). Rakovan et al. (2001) established the oxidation state of $\mathrm{Eu}$ in a powdered sample of fluorapatite from Llallagua (Bolivia) containing about $700 \mathrm{ppm} \mathrm{Eu}$ in the presence of high concentrations of $\mathrm{Mn}$ and $\mathrm{Nd}$, using a highresolution wavelength-dispersive spectrometer (WDS) to resolve the interferences. They also benefitted from higher fluxes at the sample, in the order of $10^{10}$ photons per second, by using an insertion-device beamline. For the present experiment, we wanted to test whether a less demanding analytical set-up, including a solid-state spectrometer (where all elements of interest can be investigated at the same time, as opposed to the WDS detector, in which the analyzing crystal and detector have to be scanned to measure a range of wavelengths) and a bending magnet beamline would be sufficient to obtain useful information on a natural mineral such as scheelite. Compared to fluorapatite, scheelite has the advantage that it contains very little manganese, in most cases, less than $20 \mathrm{ppm}$ (Table 1).

\section{SAMPLE DESCRIPTION AND PREPARATION}

Sample DRY1 consists of scheelite associated with fluorapatite in a quartz vein from the Drysdale stockwork (level $-160 \mathrm{~m}$ ) at Kalgoorlie, Western Australia (Brugger et al. 2000b). Kalgoorlie is located in the Yilgarn Craton, which exposes more than 1.25 million $\mathrm{km}^{2}$ of Early to Late Archean terranes (e.g., Drummond et al. 1997). Drysdale is a subeconomic occurrence of gold similar in style of mineralization and genesis to the Mt. Charlotte mine (total production of $67 \mathrm{t} \mathrm{Au}$ until 1987; Clout et al. 1990). Gold mineralization at Mt. Charlotte occurs within a series of quartz vein stockworks and associated alteration halos (Clout et al. 1990). The vein mineralogy consists of coarsely crystalline to massive quartz, with dispersed grains of calcite, siderite, albite, pyrite, and scheelite, fine-grained subidiomorphic fluorapatite, native gold, subordinate tellurides, and late chlorite and calcite (Clout et al. 1990). Hydrothermal muscovite in the alteration halo provides

TABLE 1. RESULTS OF LASER-ABLATION ICP-MS ANALYSES OF SCHEELITE FROM STEPNYAK AND DRYSDALE

$\begin{array}{llllllllllllllllllllllll}\text { Mn } & \mathrm{Ni} & \mathrm{As} & \mathrm{Sr} & \mathrm{Y} & \mathrm{Nb} & \mathrm{Mo} & \mathrm{La} & \mathrm{Ce} & \mathrm{Pr} & \mathrm{Nd} & \mathrm{Sm} & \mathrm{Eu} & \mathrm{Gd} & \mathrm{Tb} & \mathrm{Dy} & \mathrm{Ho} & \mathrm{Er} & \mathrm{Tm} & \mathrm{Yb} & \mathrm{Lu} & \mathrm{Ta} & \mathrm{Pb}\end{array}$

\section{USP31, Stepnyak, Kazakhstan}

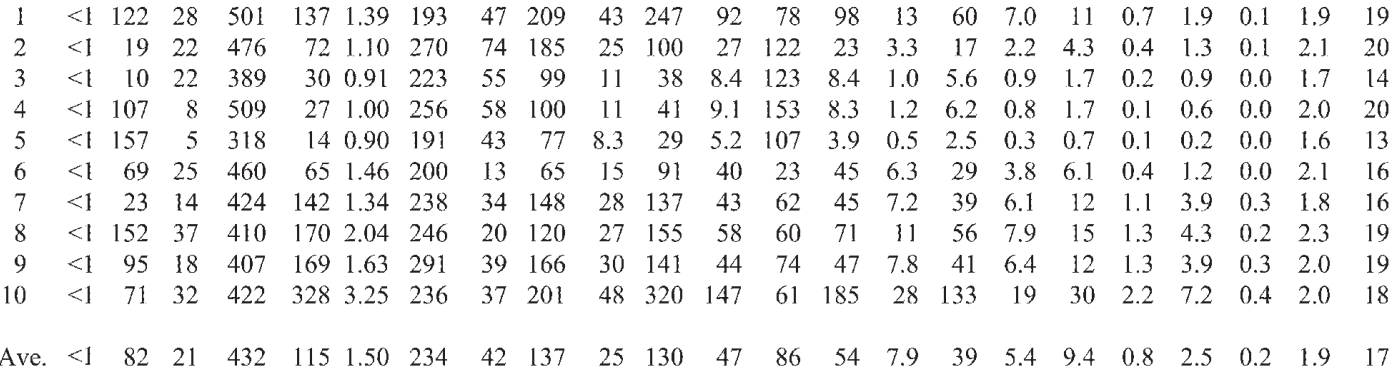

DRY1, Drysdale Stockwork, Kalgoorlie, Western Australia

$\begin{array}{rrrrrrrrrrrrrrrrrrrrrrrr}1 & 2.8 & 21 & 2073 & 542 & 1.11 & <0.5 & 17 & 126 & 37 & 295 & 190 & 126 & 264 & 41 & 202 & 30 & 63 & 7.4 & 35 & 3.7 & 1.5 & 46 \\ 2 & 0.6 & 8 & 1323 & 275 & 1.02 & 0.5 & 5.1 & 46 & 16 & 134 & 100 & 64 & 138 & 22 & 106 & 15 & 31 & 4.0 & 19 & 2.0 & 1.5 & 40 \\ 3 & 6.0 & 17 & 1597 & 1386 & 1.35 & 1.4 & 56 & 382 & 95 & 578 & 275 & 350 & 379 & 61 & 340 & 58 & 140 & 19 & 107 & 12 & 1.7 & 55 \\ 4 & 0.2 & 6 & 1264 & 139 & 0.83 & <0.5 & 5.4 & 48 & 17 & 147 & 106 & 47 & 132 & 18 & 73 & 9.0 & 15 & 1.5 & 7.2 & 0.6 & 1.6 & 35 \\ 5 & 1.7 & 30 & 1658 & 3366 & 1.46 & <0.5 & 58 & 405 & 105 & 682 & 341 & 350 & 465 & 71 & 384 & 63 & 143 & 18 & 97 & 10 & 1.7 & 51 \\ 6 & 5.7 & 5 & 1680 & 123 & 0.66 & <0.5 & 5.3 & 49 & 16 & 144 & 104 & 46 & 124 & 17 & 70 & 8.1 & 13 & 1.3 & 5.7 & 0.5 & 1.5 & 37 \\ 7 & <0.2 & 8 & 1392 & 160 & 0.90 & <0.5 & 5.4 & 58 & 22 & 193 & 133 & 59 & 160 & 22 & 91 & 11 & 18 & 1.7 & 8.0 & 0.7 & 1.5 & 36 \\ 8 & 2.7 & 5 & 1256 & 460 & 1.04 & <0.5 & 14 & 116 & 36 & 280 & 188 & 118 & 242 & 34 & 167 & 25 & 49 & 5.6 & 26 & 2.6 & 1.5 & 42 \\ & & & & & & & & & & & & & & & & & & & & & & & \\ \text { Ave. } & 2.8 & 10 & 1530 & 556 & 1.05 & 0.9 & 21 & 154 & 43 & 307 & 180 & 145 & 238 & 36 & 179 & 27 & 59 & 7.2 & 38 & 4.1 & 1.6 & 43\end{array}$

Results are expressed in ppm. 
an $\mathrm{Ar}-\mathrm{Ar}$ age of $2602 \pm 8$ m.y., interpreted as the age of the mineralization (Kent \& McDougall 1995). Desulfidation of an $\mathrm{H}_{2} \mathrm{~S}$-rich fluid (molality $\sim 10^{-5}$ ) by reaction with wallrock Fe-rich silicates and carbonates contributed to the precipitation of gold from aqueous bisulfide complexes (Mikucki \& Heinrich 1993, Mernagh et al. 2004). The relatively high grade of the Mt. Charlotte stockwork is interpreted as resulting from unusually sharp temperature-gradients $\left(\sim 220\right.$ to $\left.300^{\circ} \mathrm{C}\right)$ developed at the mine scale along fluid-flow paths (Mikucki \& Heinrich 1993, Mernagh et al. 2004).

Sample USP31 consists of scheelite in a quartzcalcite matrix from the Stepnyak deposit, northern Kazakhstan, which has produced $\sim 25 \mathrm{t}$ of gold (Spiridonov 1995). The ores at Stepnyak are associated with a Caledonian intrusive complex (diorite, tonalite, granodiorite). The ore-forming fluids were characterized by $\mathrm{T}$ $\leq 370^{\circ} \mathrm{C}, \mathrm{P} \leq 3.6 \mathrm{kbar}$, salinity $\leq 17 \% \mathrm{NaCl}$ equivalent, $\mathrm{CO}_{2} \leq 7 \mathrm{~mol} / \mathrm{kg}, \mathrm{CH}_{4} \leq 2.5 \mathrm{~mol} / \mathrm{kg}, \mathrm{P}\left(\mathrm{H}_{2} \mathrm{~S}\right) \leq 2.5 \mathrm{kbar}$; the mineralization shows a strong depth-controlled zoning, from shallow gold \pm Ag-sulfosalt \pm antimonite and gold - galena - sulfantimonides to gold - galena - tellurides and gold - tellurides in the abyssal zone (pressure from 2 to $3.6 \mathrm{kbar}$; Spiridonov 1995).

USP31 and DRY1 are vein fragments containing millimetric crystals of scheelite. The samples were embedded in epoxy resin $(25.4 \mathrm{~mm}$ diameter, $1 \mathrm{~mm}$ thick) and freshly polished to $1 \mu \mathrm{m}$ flatness.

\section{EXPERIMENTAL Methods}

Laser-ablation inductively coupled plasma - mass spectrometry (LA-ICP-MS) analyses were performed with a NewWave $266 \mathrm{~nm}$ UV laser (beam 30 $\mu \mathrm{m}$ in diameter) and a Finnigan (ThermoQuest) MAT ELEMENT ICP-MS located at Monash University. Analytical details are provided in Table 1 of Brugger et al. (2000b).

The XANES spectra were collected at beamline 2-BM-B at the Advanced Photon Source (APS) at Argonne National Laboratory, USA. Beamline 2-BM-B has a Kohzu double Si (111) monochromator, resulting in an energy resolution $\mathrm{E} / \Delta \mathrm{E}$ of $1.4 \times$ $10^{-4}$. Two Kirkpatrick-Baez (KB) mirrors at an incident angle of 4 mrad suppressed the third-order reflection from the $\mathrm{Si}(111)$ monochromator down to $0.3 \%$. The $\mathrm{KB}$ mirrors are contained in a He-filled box with 0.5 $\mathrm{mm}$ Kapton window in order to reduce the air-induced scatter and prevent surface oxidation (Eng et al. 1998). The KB mirrors focused the beam to $7 \times 7 \mu \mathrm{m}^{2}$ at the sample (sitting in air). Two ionization chambers placed before the sample were used to monitor the intensity of the incident beam. A single-channel Si drift diode (SDD) detector (Iwanczik et al. 1996), fitted with a collimator, was located at $\sim 90^{\circ}$ to minimize detection of the scattered X-ray beam. The XANES spectra were measured by scanning the beam energy over the $\mathrm{Eu} L_{3}$ absorption edge $(6977 \mathrm{eV})$ while collecting counts in a region of interest centered around the $\mathrm{Eu} L \alpha_{1}$ peak fluorescence line $(5849.5 \mathrm{eV})$. The scans were performed from 6.9 to $7.1 \mathrm{keV}$ and from 6.96 to $7.0 \mathrm{keV}$ in steps of 0.5 and $0.3 \mathrm{eV}$, respectively, with counting times ranging from 8 to $30 \mathrm{~s}$ per step. At these energies, the incident flux was between $10^{6}$ and $10^{7}$ photons $/ \mathrm{s}$ at the sample. The monochromator energy was calibrated by using synthetic scheelite doped with $\sim 6 \mathrm{wt} \% \mathrm{Eu}^{3+}$, synthesized in a $\mathrm{NaCl}$ melt according to the method described by Gaft et al. (1999). The XANES spectrum of this sample is similar to that obtained on synthetic $\mathrm{Eu}_{2} \mathrm{O}_{3}$. The position of the $\mathrm{Eu}^{3+}$ edge was obtained by fitting the XANES spectrum with a pseudo-Voigtian peak, a linear background, and an arc-tangent step function (Fig. 1a); a shift of $-1.27 \mathrm{eV}$ was applied to bring the peak position to the literature value of 6981.7 $\mathrm{eV}$ (see below).

Fluorescence images were collected at both 2-BM-B $(10.0 \mathrm{keV})$ and 2-ID-E $(9.9 \mathrm{keV})$ for 6.3 hours and 3.5 hours, respectively. The excitation energy was chosen to be below the $\mathrm{W} L_{3}$ edge $(10.207 \mathrm{keV})$ in order to minimize background in the region of the spectrum that hosts the REE. Beamline 2-ID-E is a side-branch beamline that uses a silicon crystal beam-splitter as a singlebounce monochromator. For these experiments, a zone plate $320 \mu \mathrm{m}$ in diameter with an outermost zone-width of $100 \mathrm{~nm}$ was used (focal length of $24.75 \mathrm{~cm}$ at 9.9 $\mathrm{keV}$ in the first-order diffraction), resulting in a focused beam-spot of $0.7 \times 0.4 \mu \mathrm{m}^{2}$. The sample chamber was flushed with He gas mixture to reduce absorption of X-ray fluorescence and to decrease the background fluorescence from $\mathrm{Ar}$ in air. An order-sorting aperture intercepted higher-order diffraction maxima and, in conjunction with a central stop, blocked the unfocused beam. A three-element Ge energy-dispersion detector (Canberra) was located at $\sim 90^{\circ}$ to minimize detection of the scattered beam and fitted with a conical collimator to suppress scattered X-rays and background fluorescence not coming from the sample.

The fluorescence images and spectra collected on USP31 were analyzed using GeoPIXE II (Ryan 2000). GeoPIXE II, as the name suggests, was originally developed to analyze proton-induced X-ray emission (PIXE) data and uses the Dynamic Analysis (DA) method to project quantitative images of element distribution. The DA technique is a matrix-transform algorithm that unfolds overlaps and subtracts background, escape peaks and other detector artifacts. GeoPIXE II has been extended for use with energy-dispersion synchrotron X-ray fluorescence (SXRF) data (Ryan et al. 2005). To make the transition to SXRF, it was necessary to modify the program to calculate accurate theoretical X-ray yields generated by incoming photons for a given composition of sample, experimental geometry and beam energy. X-ray yields and relative intensities reflect sub-shell ionization cross-sections, Coster-Kronig transition rates for the $L$ shell, and fluorescence yields. Sub-shell absorption cross-sections use 


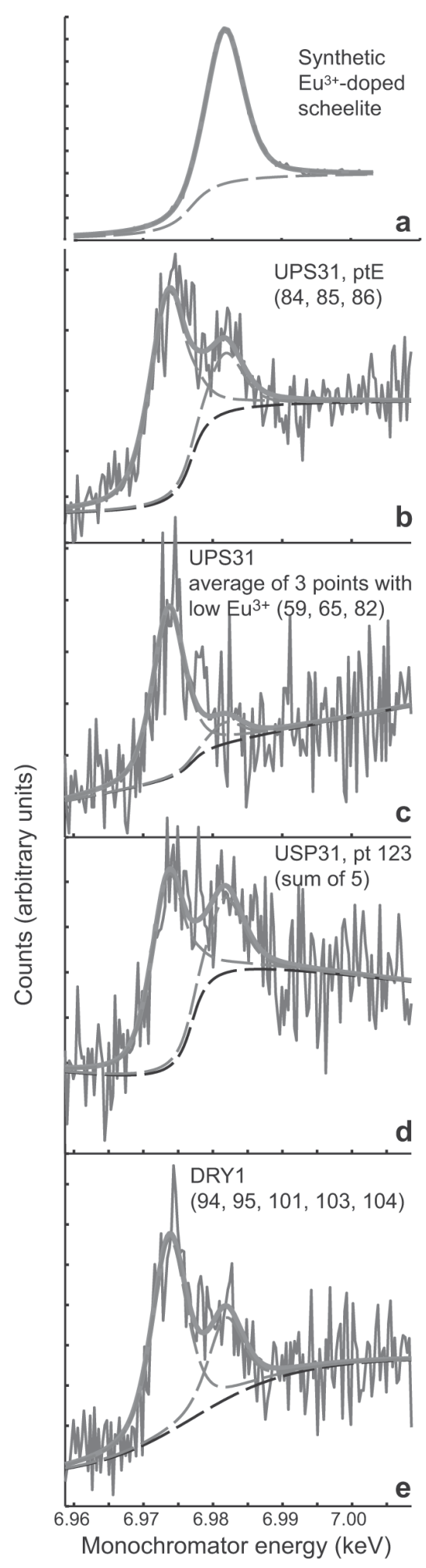

the recent compilations of Ebel et al. (2003), and the Coster-Kronig rates, fluorescence yields and branching ratios rely on the fundamental parameter database of Elam et al. (2002).

\section{RESULTS}

The fluorescence spectra collected at 2-BM-B and 2-ID-E show the presence of the rare earths, with the 2-ID-E spectra featuring a somewhat higher energyresolution than 2-BM-B (Fig. 2). In addition to elastic $(10 \mathrm{keV})$ and Compton scattered radiation, the spectra show a prominent feature around $8 \mathrm{keV}$, which arises from resonant Raman scattering on the major element W in the sample (e.g., Briand et al. 1981, Surić et al. 1991). This area of the spectrum and the peaks due to the scattered beam were excluded in fitting the spectrum in GeoPIXE. Calcium was used as an internal standard to quantify the flux (stoichiometric value of $13.9 \mathrm{wt} \%$ ). The following elements were included in the fitting procedure: Si, Ar, Ca, Mo, $\mathrm{La}, \mathrm{Ce}, \mathrm{Pr}, \mathrm{Nd}, \mathrm{Sm}, \mathrm{Eu}, \mathrm{Gd}$, Dy and Er. Apart from $\mathrm{La}$ and Ce, all REE overlap to some extent, making the quantitative determination of REE in natural samples delicate, even with the use of high-resolution WDS spectrometers (Williams 1996). As can be seen in Figure 3, the concentrations obtained by the GeoPIXE spectral fitting are of the right order of magnitude, and the changes observed in the quantitative DA maps appear to be real. The errors provided by GeoPIXE for the concentrations of the individual REE arise from counting statistics only and are estimated from the error matrix generated in the fit using the method of Bevington (1969), and scaled by the square root of reduced chi-squared of the major line for each element to account for residual systematic deficiencies in the fitting model (Ryan et al. 1990). They vary between 10 and $20 \%(1 \sigma)$; these values are an underestimation of the error for the different REE, owing to the strong overlap among the different REE and the resulting colinearity among the concentrations of the different REE. The GeoPIXE II software hence enables semiquantitative analysis of the samples for the REE, despite the low concentrations of the REE and the low spectral resolution. This capability is important for selecting areas in the sample with different REE compositions for XANES analysis.

Sample USP31 has a very inhomogeneous distribution of the REE, with chondrite-normalized patterns

FIG. 1. Europium $L_{3}$-edge XANES data for (a) synthetic scheelite doped with $\mathrm{Eu}^{3+}$, (b-d) three different locations on sample USP31 and (e) scheelite DRY1. The fits were obtained using two pseudo-Voigtian peaks (50\% Gaussian and $50 \%$ Lorentzian contribution, a value obtained from the synthetic scheelite doped with $\mathrm{Eu}^{3+}$ ) centered at 6973.7 $\left(\mathrm{Eu}^{2+}\right)$ and $6981.7\left(\mathrm{Eu}^{3+}\right) \mathrm{eV}$, a linear background and an arc tangent step-function. 

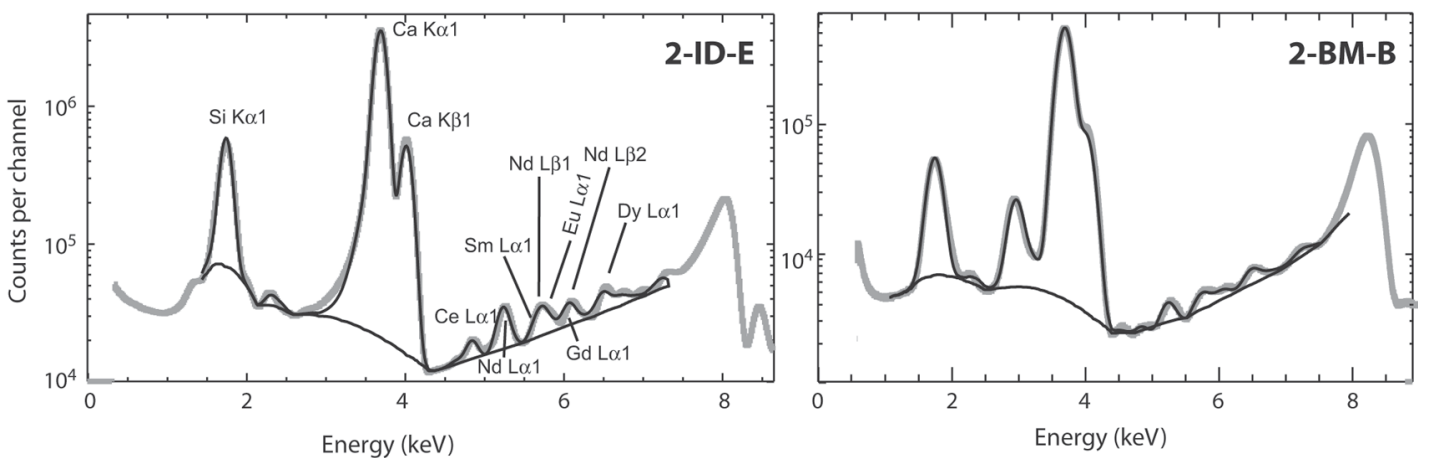

FIG. 2. Energy-dispersion spectra of scheelite USP31 collected at 2-BM-B and 2-ID-E (dark grey); the spectral fit and background obtained by the program GeoPIXE are shown as black overlays.

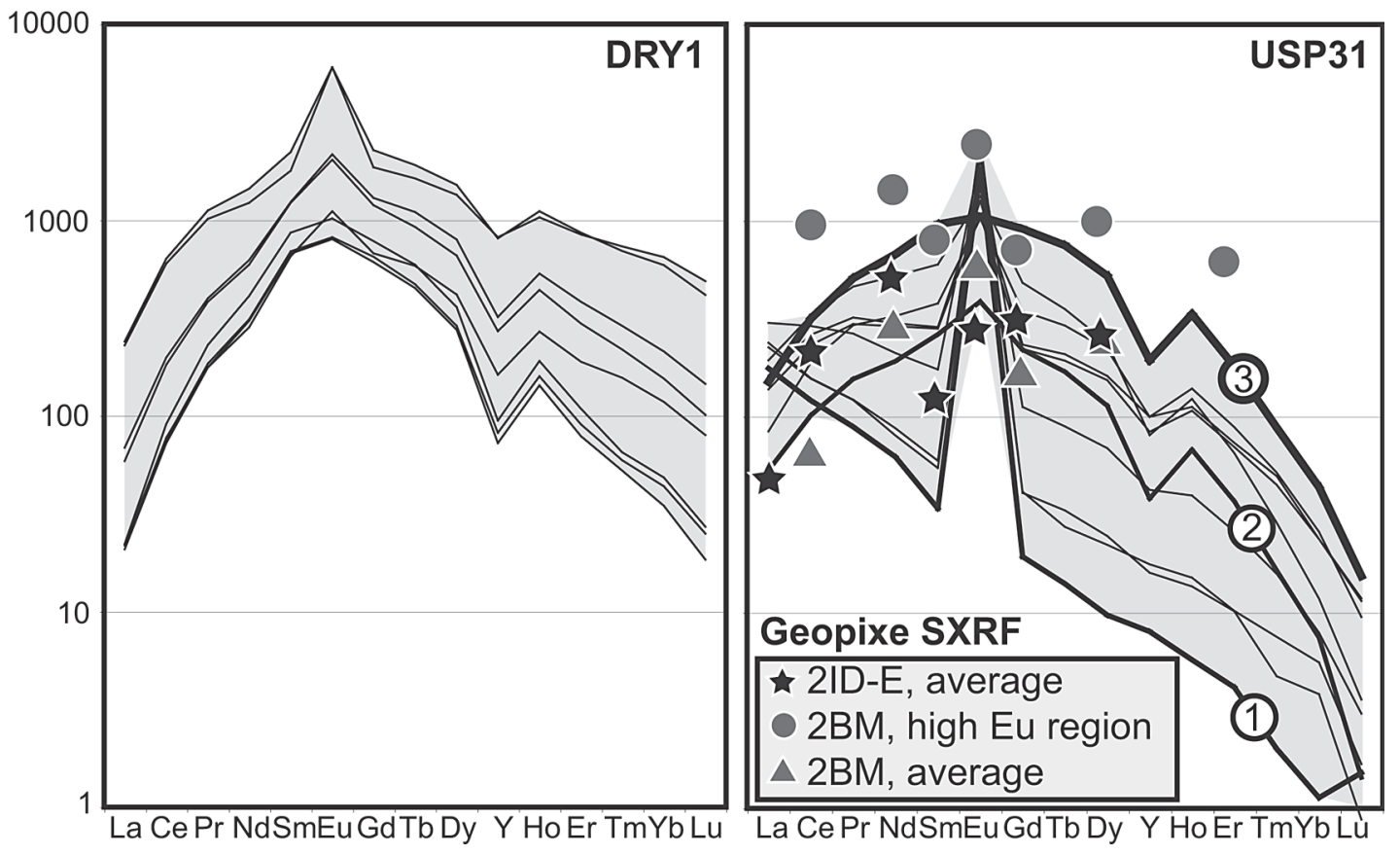

FIG. 3. Chondrite-normalized (Evensen et al. 1978) REE patterns from scheelite USP31 and DRY1 obtained by LA-ICP-MS and SXRF. Individual LA-ICP-MS analyses are shown as lines, and the range of concentrations is emphasized by a grey surface. The patterns labeled (1) and (3) for USP31 represent end-member compositions, whereas pattern (2) is parallel to (3), but with about half the concentration. Concentrations obtained by SXRF on USP31 using the GeoPIXE software are shown as symbols; a missing symbol for an element indicates that this element was below detection limit.

plotting between two end-member compositions (Fig. 3): very steep enrichment in the light REE (LREE; La to Eu), with a highly positive Eu anomaly [anal. (1) in Fig. 3] and enrichment in medium REE-enriched pattern (MREE; Eu to Lu) with a maximum enrichment at Eu with a small positive Eu anomaly [e.g., anal. (2)] or none at all [anal. (3) in Fig. 3]. The absolute concentrations can also vary by almost an order of magnitude [e.g., anal. (2) and (3) in Fig. 3]. The geometry of the zoning cannot be understood from the LA-ICP-MS 
profile. The elemental maps (Fig. 4) reveal a patchy pattern of zoning, with regions that can be related to the REE patterns measured by LA-ICP-MS ( $c f$. Figs. 3, 4): (1) high $\mathrm{Ce}$ and $\mathrm{Nd}$, low $\mathrm{Eu},(2)$ high $\mathrm{Ce}$ and $\mathrm{Eu}$, low $\mathrm{Nd}$, and (3) low $\mathrm{Ce}, \mathrm{Nd}$ and $\mathrm{Eu}$.

DRY1, on the other hand, shows only one type of REE pattern, enriched in the MREE with a maximum between $\mathrm{Eu}$ and $\mathrm{Gd}$, and a small positive Eu anomaly or none at all. The total concentration of the REE varies over almost an order of magnitude (Table 1).

The XANES data obtained for the natural minerals are noisy, a result of the low concentration of Eu and a relatively low incident flux (Figs. 1b-e). In addition, the $\mathrm{Nd} L \beta$ interference results in peak-to-background ratios not exceeding $\sim 2$. Among the many samples of scheelite analyzed by LA-ICP-MS, USP31 and DRY1 are characterized by unusually high Eu/Dy values. This anomaly results in high Eu concentration and relatively reduced $\mathrm{Nd}$ interference, and only these two samples were suitable for measurement with the apparatus used in the present study. Two XANES spectra collected on different regions of USP31 (Figs. 1b, d) are very similar. The first peak clearly appears at the position of the $\mathrm{Eu}^{2+}$ resonance-peak. As the intensity of the $\mathrm{Eu}^{3+}$ edge resonance-peak is 1 to 1.5 times larger than that

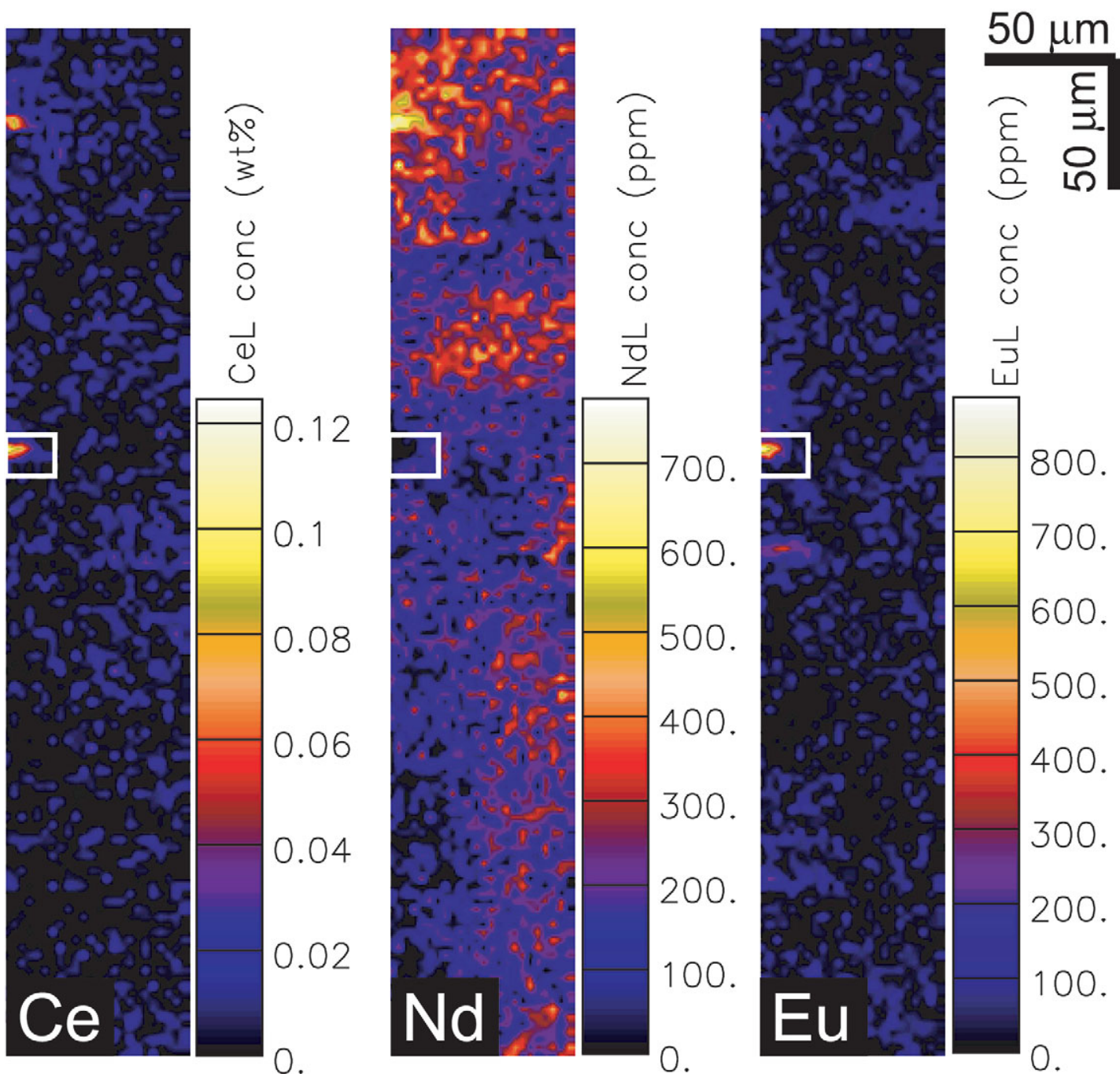

FIG. 4. Semiquantitative element-distribution maps for scheelite USP31 collected at beamline 2-BM-B (beam-size $7 \mu \mathrm{m} ; 134$ $\times 24$ points; 5 seconds per point) and processed using the GeoPIXE software, DA method. The rectangle shows the area integrated to obtain the REE pattern entitled "High-Eu region" on Figure 3. 
of $\mathrm{Eu}^{2+}$ (Rakovan et al. 2001), most Eu exists in the 2+ oxidation state at these two spots. However, there is a clear shoulder at the position of the $\mathrm{Eu}^{3+}$ resonancepeak, indicating the presence of significant $(>10 \%)$ amounts of $\mathrm{Eu}^{3+}$ as well. Other regions seem to lack this shoulder (Fig. 1c), and hence contain in excess of $90 \% \mathrm{Eu}^{2+}$. Sample DRY1 shows a XANES spectrum relatively similar to that of point E on USP31 (Figs. 1b, e), indicating a predominance of $\mathrm{Eu}^{2+}$ coexisting with significant amounts of $\mathrm{Eu}^{3+}$.

\section{Discussion}

The study of REE distribution and speciation in hydrothermal minerals is made difficult by low concentrations, spectral overlaps, and complex zoning at the scale of 1 to $10 \mu \mathrm{m}$. However, with synchrotron-based $\mathrm{XRF}$ and XANES techniques, it is possible to obtain semiquantitative information about the concentration, pattern of zoning, and oxidation state of REE in situ in hydrothermal scheelite. In the two samples studied, $\mathrm{Eu}$ exists in a mixed oxidation state $\left(\mathrm{Eu}^{2+}\right.$ and $\left.\mathrm{Eu}^{3+}\right)$. Similar evidence for mixed-valence Eu was obtained by Rakovan et al. (2001) for a sample of powdered hydrothermal fluorapatite, suggesting that hydrothermal minerals commonly contain a mixture of $\mathrm{Eu}^{2+}$ and $\mathrm{Eu}^{3+}$. The apparently inhomogeneous distribution of $\mathrm{Eu}^{2+}$ and $\mathrm{Eu}^{3+}$ in USP31 suggests that $\mathrm{Eu}^{2+} / \mathrm{Eu}^{3+}$ may be preserved in scheelite over hundreds of millions of years, and that diffusion does not affect this ratio severely, at least for the conditions prevailing during the geological history of USP31.

This study hence paves the way for systematic studies of the oxidation state of Eu in hydrothermal minerals. Quantitative data on a large variety of samples can be obtained by using an insertion-device beamline (higher flux) and a WDS spectrometer to minimize the $\mathrm{Nd} L \beta$ interference. Such studies will help in the interpretation of REE data in complex hydrothermal environments. For example, the range of REE distribution in scheelite from Archean gold deposits has been interpreted both in terms of open-system change in the oxidation state of the ore-forming fluids (Ghaderi et al. 1999), and in terms of closed-system fractional crystallization (Brugger et al. 2000a, b, 2002). These two contrasting interpretations could be discriminated by measuring the ratio $\mathrm{Eu}^{2+} / \mathrm{Eu}^{3+}$ in the finely (1-10 $\mu \mathrm{m})$ zoned grains of scheelite.

\section{ACKNOWLEDGEMENTS}

This work was supported by the Australian Synchrotron Research Program, which is funded by the Commonwealth of Australia under the Major National Research Facilities Program. Use of the Advanced Photon Source was supported by the U.S. Department of Energy, Office of Science, Basic Energy Sciences, under Contract No. W-31-109-Eng-38. We are grateful to Evgeniy Uspensky (Moscow) for providing sample USP31 and Francesco de Carlo for assisting with the experimental setup. The manuscript benefitted from the careful reviews by M. Newville, S. Mignardi, R.F. Martin and C. Aurisicchio.

\section{REFERENCES}

Anglin, C.D., Jonasson, I.R. \& FrankLin, J.M. (1996): Sm-Nd dating of scheelite and tourmaline - implications for the genesis of Archean gold deposits, Val d'Or, Canada. Econ. Geol. 91, 1372-1382.

BAU, M. (1991): Rare-earth element mobility during hydrothermal and metamorphic fluid - rock interaction and the significance of the oxidation state of europium. Chem. Geol. 93, 219-230.

Bevington, P.R. (1969): Data Reduction and Error Analysis for the Physical Sciences. McGraw-Hill, New York, N.Y.

Briand, J.P., Girard, D., Kostroun, V.O., Chevalier, P., WoHrer, K. \& Mossé, J.-P. (1981): X-Ray Raman and Compton scattering in the vicinity of a deep atomic level. Phys. Rev. Lett. 46, 1625-1628.

Brugger, J., Bettiol, A.A., Costa, S., Lahaye, Y., Bateman, R., LAMBERT, D.D. \& JAMieson, D.N. (2000a): Mapping REE distribution in scheelite using luminescence. Mineral. Mag. 64, 891-903.

Brugger, J., Lahaye, Y., Costa, S., Lambert, D. \& Bateman, R. (2000b): Inhomogeneous distribution of REE in scheelite and dynamics of Archaean hydrothermal systems (Mt Charlotte and Drysdale gold deposits, Western Australia). Contrib. Mineral. Petrol. 139, 251-264.

Brugger, J., Maas, R., Lahaye, Y., McRae, C., Ghaderi, M., Costa, S., Lambert, D., Bateman, R. \& Prince, K. (2002): Origins of $\mathrm{Nd}-\mathrm{Sr}-\mathrm{Pb}$ isotopic variations in single scheelite grains from Archaean gold deposits, Western Australia. Chem. Geol. 182, 203-225.

Clout, J.M.F., Cleghorn, J.H. \& Eaton, P.C. (1990): Geology of the Kalgoorlie gold field. In Geology of the Mineral Deposits of Australia and Papua New Guinea (F.E. Hughes, ed.). The Australian Institute of Mining and Metallurgy, Melbourne, Australia (411-431).

Drummond, B.J., Goleby, B.R. \& Swager, C.P. (1997): Crustal signature of the major tectonic episodes in the Yilgarn Block, WA: evidences from deep seismic sounding. In Kalgoorlie 97: an International Conference on Crustal Evolution, Metallogeny and Exploration of the Yilgarn Craton - an Update (K.F. Cassidy, A.J. Whitaker \& S.F. Liu, eds.). Aust. Geol. Surv. Organisation, Extended Abstr., Rec. 1997/41, 15-20.

Ebel, H., Svagera, R., Ebel, M.F., Shaltout, A. \& HubBELL, J.H. (2003): Numerical description of photoelectric absorption coefficients for fundamental parameter programs. X-Ray Spectrometry 32, 442-451. 
EICHHORN, R., HöLl, R., JAGOUTZ, E. \& SCHÄRER, U. (1997): Dating scheelite stages: a strontium, neodymium, and lead approach from the Felbertal tungsten deposit, central Alps, Austria. Geochim. Cosmochim. Acta 61, 5005-5022.

Elam, W.T., Ravel, B.D. \& Sieber, J.R. (2002): A new atomic database for X-ray spectroscopic calculations. Radiation Phys. Chem. 63, 121-128.

ENG, P.J., Newville, M., Rivers, M.L. \& Sutton, S.R. (1998): Dynamically figured Kirkpatrick-Baez X-ray micro-focusing optics. In X-Ray Microfocusing: Applications and Technique (I. McNulty, ed.). SPIE Proc. 3449, 145-156.

Evensen, N.M., Hamilton, P.J. \& O’Nions, R.K. (1978): Rare-earth abundances in chondritic meteorites. Geochim. Cosmochim. Acta 42, 1199-1212.

GAFt, M., PAnczer, G., UsPensky, E. \& ReISFELD, R. (1999): Laser-induced time-resolved luminescence of rare-earth elements in scheelite. Mineral. Mag. 63, 199-210.

Ghaderi, M., Palin, M.J., Campbell, I.H. \& Sylvester, P.J. (1999): Rare earth element systematics in scheelites from hydrothermal gold deposits in the Kalgoorlie-Norseman region, Western Australia. Econ. Geol. 94, 423-437.

GIERÉ, R. (1996): Formation of rare earth minerals in hydrothermal systems. In Rare Earth Minerals: Chemistry, Origin and Ore Deposits (A.P. Jones, F. Wall \& C.T. Williams, eds.). Chapman \& Hall, London, U.K. (105-150).

HAAS, J.R., SHOCK, E.L. \& SASSANI, D.C. (1995): Rare earth elements in hydrothermal systems: estimates of standard partial molal thermodynamic properties of aqueous complexes of the rare earth elements at high pressures and temperatures. Geochim. Cosmochim. Acta 59, 4329-4350.

Heinrich, C.A., Walshe, J.L. \& Harrold, B.P. (1996): Chemical mass transfer modelling of ore-forming hydrothermal systems: current practice and problems. Ore Geol. Rev. 10, 319-338.

Iwanczyk, J.S., Patt, B.E., Segal, J., Plummer, J., Vilkelis, G., Hedman, B., Hodgson, K.O., Cox, A.D., Rehn, L. \& METZ, J. (1996): Simulation and modelling of a new silicon $\mathrm{X}$-ray drift detector design for synchrotron radiation applications. Nucl. Instrum. Meth. A 380, 288-294.

Kent, A.J.R. \& McDougall, I. (1995): ${ }^{40} \mathrm{Ar}-{ }^{39} \mathrm{Ar}$ and U-Pb age constraints on the timing of gold mineralization in the Kalgoorlie gold field, Western Australia. Econ. Geol. 90, 845-859.

LiPIN, B.R. \& McKAY, G.A., eds. (1989): Geochemistry and mineralogy of rare earth elements. Rev. Mineral. 21.
Mernagh, T.P., Heinrich, C.A. \& Mikucki, E.J. (2004): Temperature gradients recorded by fluid inclusions and hydrothermal alteration at the Mount Charlotte gold deposit, Kalgoorlie, Australia. Can. Mineral. 42, 1383-1403.

MikucKi, E.J. \& HeinRICH, C.A. (1993): Vein- and mine-scale wall-rock alteration and gold mineralization in the Archean Mount Charlotte deposit, Kalgoorlie, Western Australia. Aust. Geol. Surv. Organisation, Rec. 1993/54, 135-140.

Rakovan, J., Newville, M. \& Sutton, S. (2001): Evidence of heterovalent europium in zoned Llallagua apatite using wavelength dispersive XANES. Am. Mineral. 86, 697-700.

RYAN, C.G. (2000): Quantitative trace element imaging using PIXE and the nuclear microprobe. Int. J. Imaging Systems Technol. 11, 219-230.

Ryan, C.G., Cousens, D.R., Sie, S.H., Griffin, W.L., Suter, G.F. \& Clayton, E. (1990): Quantitative PIXE microanalysis of geological material using the CSIRO proton microprobe. Nucl. Instrum. Meth. B 47, 55-72.

Ryan, C.G., Etschmann, B.E., Vogt, S., Maser, J., Harland, C.L., van ACHTERBERGH, E. \& LegNinI, D. (2005): Nuclear microprobe - synchrotron synergy: towards integrated quantitative real-time elemental imaging using PIXE and SXRF. Nucl. Instrum. Meth. B 231, 183-188.

SPIRIDONOv, E.M. (1995): The inversional plutonogenic goldquartz association of the northern Kazakhstan Caledonides. Geol. Ore Deposits 37(3), 149-175 (in Russ.).

Surić, T., Bergstrom, P.M., Pisk, K. \& Pratt, R.H. (1991): Compton scattering of photons by inner-shell electrons. Phys. Rev. Lett. 67, 189-192.

SVERJENSKY, D.A. (1984): Europium redox equilibria in aqueous solution. Earth Planet. Sci. Lett. 67, 70-78.

Uspensky, E., Brugger, J. \& Graeser, S. (1998): REE geochemistry systematics of scheelite from the Alps using luminescence spectroscopy: from global regularities to facies control. Schweiz. Mineral. Petrogr. Mitt. 78, 33-56.

WiLliams, C.T. (1996): Analysis of rare earth minerals. In Rare Earth Minerals: Chemistry, Origin and Ore Deposits (A.P. Jones, F. Wall \& C.T. Williams, eds.). Chapman \& Hall, London, U.K. (327-348).

Received March 10, 2005, revised manuscript accepted June 15, 2006. 